\title{
Distance learning: the practice of intercommunication between a tutor and students
}

\author{
Tatiana Zhubreva ${ }^{1, *}$ \\ ${ }^{1}$ Moscow Technological Institute, 199334, Moscow, Russia
}

\begin{abstract}
The conducted investigation has included monitoring of the provision of educational services in a remote mode - distance-learning format for adult students at Moscow Business School (MBS). It is aimed at finding best approaches for increasing a degree of "reaching" every student. The problem is that some people, including potential candidates for distance-learning programs, blame distance education for the lack of communication with teacher/tutor. They say that distance learning does not allow applying the principles of customization to it; for some of them there is no difference between E-learning and distance learning. The results of this action research show rather clearly that there are ways in the framework of distance education to use an individual approach for each of the students by the tutors. Some types of intercommunication with students in written form could be rather exhausting ones, but others could be successfully carried out by a creative tutor
\end{abstract}

\section{Introduction}

The content of postgraduate education in Russia is defined by the education reform that provides educational institutions with more opportunities in the development of educational programs, filling them with content that matches the needs of potential and present students. As a result, postgraduate education becomes more flexible, able to respond not only to the needs of a labor market, but also to the interests of an individual.

Nowadays, there are many business schools in Russia, which suggest education in a distance format, and the competition for students is rather strong. According to the [1] Moscow Business School occupies the 74th place out of 112 listed schools, while its program "MBA Start" takes the 11th place out of 25 shown in this rating list [2]. The program "MBA Start" has been introduced to the educational market at the beginning of 2008, and it is fully distant. During all the years, tutors have been making every possible endeavor to meet the natural need of students in individual communication with tutors. Constant investigations, data analysis and continuous improvement help to bridge the gap between the student and the tutor.

\section{Literature Review}

\subsection{E-learning vs Distance Education}

Distance education around the world is widely used for professional higher education, postgraduate programs, and training. "Free access to knowledge is an important tool for economic, cultural and social development" $[3$, p. 29]. However, some people, at least in Russia, hardly understand all the possibilities of this type of education, there is no sustainable understanding of the nature of the service. "Distance format is usually identified with Elearning - exclusively electronic online self-study. However, this is not quite correct, since E-learning is just one element of the set of information transfer technologies. Technologies can be different: E-learning, face-to-face, correspondence, etc.”, specifies the Rector of Open Business School Boris Fedorov in his interview for the journal "Expert North-West" in October 2009. [cited in 4]. The situation is changing, now we confirm, "...the most important feature of a tutor and his/her work is a highly individualized approach, which takes place rather often and at times excels academic face-to-face lessons" [5]. Distance education technology still requires explaining and clear reasoning its positive features and the ways of their augmentation.

In practice, in remote mode learning both short-term and continued, long-term training programs are introduced on educational market. As far as we make focus on MBA programs it is worth to say, that all of them split into two categories: self-study of materials provided by school and a report on the work done (usually testing, mainly in automatic mode) and selfstudy with tutor support and active interaction with the last one. In the first case, it is pure E-learning winning some customers because of rather convenient, time and money saving, format. The reality is that the majority of potential and present students prefer the second category - distance education with a tutor taking an active role, close interaction with $\mathrm{s} / \mathrm{he}$, quick and meaningful feedback. These become possible because of the Internet 
technology; tutor and student need only a PC, tablet or smartphone, with relevant software.

The advantages of the second variant of training will be discussed below. The obtained results are based on almost 10 years of experience in tutoring activities for the "MBA Start" program at the Moscow Business School and more than 25 years of experience as a teacher at classical higher school. The tutor in distance education does not just replicate book knowledge, but s/he is the link between the technology and the audience and at the same time - personality organizing information space. Today in distance education, more than ever, the priority is given to developing skills of independent searching of information, exchanging of relevant information between students, solving non-standard tasks and exploring a creative approach to their solution. All these give necessary professional knowledge and skills.

\subsection{The Role of a Tutor in Distance Education}

What is a tutor? Discussions with colleagues show that the definition of tutor's "official duties" are highly ambiguous, despite the fact that in Russia the position of tutor was formalized in the lists of educators.

However, the author of the article [6] in my opinion rightly says, "...these descriptions do not allow presenting a professional activity in its entirety - such is the nature of this format". In confirmation of the above said and my own thoughts, I will give one more quote: "In fact, there are a lot of definitions of 'tutor' ... in different cities and countries. Unfortunately, the term 'tutor' rather often is narrowed to denote a coach, mentor, supervisor, assistant, thereby not realizing the difference, ...! [5]. I agree with the next saying - "Tutor is historically a special pedagogical position, which ensures the development of individual educational programs of students and accompanies the process of individual education..." [7].

Therefore, we can see the importance of tutorial work in distance education, the importance of its continuous improvement on the base of internal investigations and communication with professional society.

\section{Research Methods}

All the investigations were conducted within the phenomenological paradigm, which is concerned with understanding human behavior; under this paradigm "...social reality is dependent on the mind" [8, p.53] of participants; the investigated phenomenon and its investigator cannot be separated.

An analytical qualitative research approach was adopted for finding the ways of increasing the level of students' involvement in educational process, and the ways of overcoming negative features (weaknesses) of distance education. According to [8, p. 11] in this type of research "the researcher goes beyond describing the characteristics, to analyzing and explaining why and how it is happening'.

The population is students, distributed administratively for the studying the materials of module 6 , where I was designated as the leading tutor. In a random sample were students who asked for tutoring support and/or submitting written work on E-seminars.

The primary research data was collected via participant observation "in a natural setting", which means full involvement of researcher "with the participants and the phenomena being researched" $[8, \mathrm{p}$. 159], when "the observer acts as both an observer and participant" [9].

The method of action research was used for the sake of constant improvement of teaching and learning processes, finding appropriate balance between spent time and the level of educational services customization. It is a type of applied research, when a researcher makes "a continuous change in a partly controlled environment" [8, p. 65] with the aim to bring about a change and to monitor the results; "and the researcher and the research itself are the part of this change" [8, p. 64]. This action research had started approximately 5 years ago, and gave rather optimistic results described below.

\section{Findings}

At Moscow Business School MBA students' teaching is carried out in a remote format with tutor support. Thus, a tutor is not only the organizer but also the teacher working with each student, taking into account the student's background and business experience, his/her personal characteristics, and the potential, both an individual student or a group of students as a whole. Individualization of the approach is provided by an IT technology to support learning and teaching processes (platform Mirapolis). MBS internal documents, regulating the duties of tutors, are encouraging the individual work with each student. However, we have to take into consideration that indepth intercommunication is time consuming that is why it is extremely important to find the balance suiting both sides: tutor and student.

Depending on the type of lessons tutors work with students differently: in the on-line mode - when conducting webinars (public defense of final qualifying works - diploma thesis - are also held in remote mode, if the student has no opportunity to attend the defense in person) and off-line - when conducting E-seminars. Eseminars are held at forum branches with different modes of access for a tutor and for students. During module 6 students have an opportunity to take part in three E-seminars (the participation is not compulsory). Testing of knowledge is obligatory for all the students; they have to pass three tests related to the main topics of module 6 for completing it.

\subsection{Knowledge Testing Procedure}

Testing takes place without a participation of tutors in an automatic mode. Each student has three attempts for passing each test. Any student has the right to appeal to a leading tutor of the module for clarification and assistance in preparation for testing and in case of failing the test. Leading tutor can monitor the process of testing using the corresponding resource, where $\mathrm{s} /$ he can see the 
number of attempts used and the obtained by student mark. S/he also has the right to mark the test upon fulfilling by student so called "work on the bugs".

During first year of program "MBA Start" running, we could observe the situation when some of students after failing their first attempt in a testing asked the tutor to mark this test on the base of "work on the bugs", as it was much easier for them to pass the test.

MBS administration has made the correcting action: it was prohibited for tutors marking "work on the bugs" before students fail all the three attempts. It worked for some time, but some tricky students found out that it was easier and less time consuming to fail all three attempts in the IT system of distance education, then make "work on the bugs" at home looking into the textbook, and receive good mark from the tutor. As soon as this mark appeared in the IT system of distance education, nobody could know how it was obtained. For some instance, it is the violation of the interests of hard-working students. The other drawback of this situation was that tutors were overloaded with checking "works on the bugs" and seemed to be underpaid for their work.

The next correcting action took place two years ago. Since that time, those students who fail all three attempts and submitted "work on the bugs" could not receive the mark more than 62 point out of 100 . Now we can observe the situation when the majority of students (approximately 98\%) successfully pass tests applying to a leading tutor only in case they need additional explanations of study materials when preparing to pass tests in the IT system of distance education. The good result is obvious - tutors can trace not very successful students and spend more time on E-seminars.

\subsection{E-seminars}

Everybody knows that a well-organized practice is the most effective tool for deepening theoretical education and applying theoretical knowledge to real business situations, as well as it is a stimulus and base to further professional growth. How in a remote format of education students can obtain not only knowledge, but also skills and to consolidate both? Usually, teachers and tutors use the method of case analysis.

Assessing the case-study technology in distance learning, V. A. Traynev with colleagues [3, p. 206] wrote that it was the first of the technologies applied for distance education. Problem based method in the form of case studies plays a significant positive role in the technology of distance education. Normally teacher or tutor uses published cases, which "are designed to expose students to the choice, challenges, opportunities, and constraints faced by...managers and to help them to develop the understanding, skills and judgment necessary to function effectively" [10] in real business world.

However, already at the very beginning of my career as a tutor for adult students it became apparent to me that students respond differently on the discussed cases. They were more enthusiastic and aimed when the core of the case was close to their background and managerial problems they face as employees or business owners day by day. They also prefer and demand cases on the topic of the day. This observation allowed me to change the nature of the tasks for E-seminars.

The first correcting action was undertaken regarding tasks of the first E-seminar. Normally students were proposed for the discussion of the standard case studies for acquiring skills of analyzing business situations (this is common practice). Then they were asked to write a case of their own as a description of problem situation they were involved in. The ways of solving such cases and giving evaluation of their own actions and the actions involved in the problem colleagues become more involved. It promoted the increased number of participants in the E-seminars as well as increased the activity and students intercommunication. One more advantage is in widening the information field about real business especially for less experienced students.

The next corrective action is described below. The best cases written by students of one group were proposed for discussion in other groups (under written permission of the authors). In contrast to standard cases, where the result of problem solving is not obvious, in hand prepared cases tutor knows how the problem was actually solved. Students are usually very interested to compare their own suggestions with the implemented methods of problem solving. Again, it helps students in the acquisition of skills for business administration.

During the third E-seminar we run a business game aimed on searching creative solutions for real business problems of the company that students work for or the owner (co-owner) of which is one of the group members. The format of the E-seminar makes it possible to discuss up to three business situations (duration of E-seminar in the off-line mode is about $8-9$ days). About $15(8-22)$ students attended this E-seminar, it creates active discussions and form live information field, in which some students are able to share existing knowledge and practices, while others get them and translate to their own business challenges and options for actions.

To make this E-seminar we started to use rather well known method of Six Thinking Hats invented by Edward de Bono. Originally, it is a meeting of six or more participants involved in searching for creative decision of an existing problem. At least five research actions were made before the most effective way of using the core rules of the game were found out and implemented in the practice of distance education. The result exceeded expectations. Some students started using the method on their working place in parallel with seminar and reported the results, showing what works and what does not. In this case students (and the tutor also!) have good opportunity to learn more about the variability of business and the ways of its administration.

\subsection{Assignments and Diploma Thesis}

Another stage of training is the preparation of a final paper on the module. It could be either an assignment or a research proposal. Individual assignments and individual feedback on works performed also soften the fact of "remoteness" of a tutor from a student. Nowadays the intention of tutors and administration is to exclude 
assignments and make research proposals compulsory for the students finishing module 6 . It seems to be a positive corrective action.

In addition to the electronic platform provided by MBS, tutors and especially supervisors of diploma thesis increasingly use cloud technologies and social networks, creating a temporary communities of students. The observation of this practice shows that in the cloud it is very convenient to monitor the activity of each student. It also helps stimulating this student activity (it is often happens that students themselves "rush" lagging group members), and to organize group discussions. Finally, close intercommunication between a tutor and students results in loyal Moscow Business School graduates.

\section{Conclusions}

Personal experience of training masters of business administration at the MBS leads to the conclusion: distance education lets you "bring" a student to a teacher with proper organization of the learning process. It happens when the management team and tutors constantly undertake corrective actions, thus making distance education no less individualized than the classroom activities in the traditional format. Especially when the creative approach of a tutor to his/her job happens.

By observing students' activities, their attitude towards study materials and given tasks, a tutor is able to see what is to be improved and what changes should be implemented for increasing students' interest and involvement in educational process.

The conducted research clearly proves a practicability of encouraging students for bringing the business experience of their own to a group study. The most optimal way for that is writing by them mini-cases and assignments on hot topics. Combined efforts of students and a tutor result in an increase of educational services customization level in distance education.

\section{References}

1. MBA ranking of business school. URL: http://www.mbatoday.ru/university/stat000.htm

2. Ranking of MBA program. URL: http://www.mbatoday.ru/university/stat001.htm

3. V.A. Traynev, V.Y. Teplyshev, I.V. Trainev, New information and communication technologies in education (Moscow, 2013)

4. Discussing distance MBA - for and against! http://www.mbatoday.ru/analytics/83.htm

5. A. N. Alferov. About tutoring activities. Interregional Union of Educators, http://pedagogprof.org/index.php? $\mathrm{id}=437$ \&Itemid $=45$ \&option $=\mathrm{co}$ m_k2\&view=item

6. M.J. Cheredilina, About the professional standard of tutor support. URL: http://worldtutors.ru/oprofessionalnom-standarte-tyutorskogosoprovozhdeniya.html

7. V.P. Sergeeva, S.I. Sergeeva, G.V. Sorokovyh, Y.V. Ziborova, L.S. Podymova, Tutor in the educational space (Moscow, 2016)

8. J. Hussey, R. Hussey. Business Research. A practical Guide for Undergraduate and Postgraduate Students (MACMILLAN PRESS LTD, 1997)

9. D. R. Cooper, P. S. Schindler, Business Research Methods (Irwin/McGraw-Hill, 2001)

10. W.E. Sasser, K.B. Clark, D.A. Garvin, M.D.W. Graham, R. Jaikumar, D.H. Maister, Cases in Operations Management. Analysis and Action (RICHARD D. IRWIN, INC, 1982) 